\title{
AISI 304 Stainless Steel as a Transducer Substrate in Electrochemical Biosensors for Medical Applications
}

\author{
Ricardo Adriano Dorledo de Faria*1, Luiz Guilherme Dias Heneine ${ }^{2}$, Vanessa de Freitas Cunha Lins ${ }^{1}$ \\ and Tulio Matencio ${ }^{3}$
}

${ }^{1}$ Department of Chemical Engineering, Universidade Federal de Minas Gerais (UFMG), Belo Horizonte, Minas Gerais 30270-901, Brazil

${ }^{2}$ Department of Applied Immunology, Fundação Ezequiel Dias (FUNED), Belo Horizonte,Minas Gerais 30510-010, Brazil

${ }^{3}$ Department of Chemistry, Universidade Federal de Minas Gerais (UFMG), Belo Horizonte, Minas Gerais 30270-901, Brazil

*Corresponding author: Ricardo Adriano Dorledo de Faria, Department of Chemical Engineering, Universidade Federal de Minas

Gerais (UFMG), Belo Horizonte, Minas Gerais 30270-901, Brazil

\section{ARTICLE INFO}

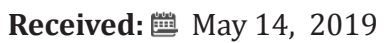

Published: May 21, 2019

Citation: FARIA, R.A.D. , Luiz Guilherme Dias H, Luiz G.D.H, Vanessa de F.C.L. AISI 304 Stainless Steel as a Transducer Substrate in Electrochemical Biosensors for Medical Applications. Biomed J Sci \& Tech Res 18(2)-2019. BJSTR. MS.ID.003117.

Keywords: Biosensor; Stainless Steel; Transducer; Electrochemical Sensing

\section{ABSTRACT}

Stainless Steels (SS) are promising candidates to constitute the transducer substrate of devices for electrochemical sensing mainly due to their high electrical conductivity, biocompatibility and relative low cost. In this study, the corrosion resistance of SS was examined in four solutions that represent the environment of biosensors in real applications: $0.01 \mathrm{M}$ Tris buffer ( $\mathrm{pH} 7.4$ ), an electrolyte containing Tris and $0.1 \mathrm{M}$ $\mathrm{KCl}$ as supporting source of ions, Hanks' solution to simulate body fluids and, also, a solution to represent the electrolyte commonly used to performed Cyclic Voltammetry (CV). Potentiodinamic anodic polarization, Chronoamperometry and images of Optical Microscopy revealed that the Hanks' and CV solutions were the most aggressive media to the SS electrodes, which remained chemically stable in both Tris and electrolyte during $16 \mathrm{~h}$ under the influence of critical potentials. When functionalized to recognize venom from Crotalus snakes, the SS suffered an increase of the diameter of the capacitive arc in the EIS experiment as a result of the detection of the target analyte, corroborating it is a promising electrochemical transducer for application in biosensors.

\section{Introduction}

For many reasons, the material sciences have focused in studies of electroanalysis, exploring the knowledge of conductive materials that can be used as sensitive elements for composing sensors in order to specifically recognize analytes of interest [1]. According to the IUPAC [2], the material responsible for providing a measurable output signal by means of a biological reaction on its surface is defined as a "transducer" and it is a crucial component of a biosensor. In electrochemical biosensors, the transduction phenomena occurs due to oxidative and reductive processes, and the charge transferring can be correlated to the concentration of a target molecule, providing a selective and sensitive detection in a simple and easyto-use format $[3,4]$. Electrochemical transduction has received larger attention due to its simplicity, low cost of instrumentation and possibility of application as miniaturized systems. Thus, among innumerous applications of biosensors, medical field has particular interest on it for requiring quick, portable and simple devices for providing early and efficacious diagnosis [5]. Nowadays, point-ofcare sensors represent about $57 \%$ of the biosensors market and it requires cost-effective platforms and materials [6]. Thereby, many studies have focused on developing high-performance biosensors, whose analytical response strongly depends on the properties of their transducers [7]. In the light of this context, Stainless Steels (SSs), which are alloys of iron containing at least $11 \% \mathrm{w} / \mathrm{w} \mathrm{Cr}$, are promising candidates for biomedical applications, since they have high corrosion resistance, great biocompatibility and low cost $[8,9]$. Due to these interesting characteristics, some researches have been devoted to the use of SSs in the field of biosensors for various applications $[8,10,11]$.

The present study aimed to evaluate the employment of 304 SS as an electrochemical transducer for biosensors of medical rel- 
evance. For this purpose, the corrosion resistance of the material was analyzed in four media where biosensors are commonly employed at their work condition: Tris buffer, which is used to prepare biological solutions and to store sensors in appropriate conditions of salt concentration and $\mathrm{pH}$ [12-14]; an electrolyte containing potassium chloride, which is an aqueous solution commonly used in the literature due to its good conductivity to perform electrochemical measurements [15,16]; Hanks' solution, which is a synthetic solution that simulates body conditions and it is one option constantly considered in corrosion studies of environmental body influence [17-20]; and a $\mathrm{K}_{3}\left[\mathrm{Fe}(\mathrm{CN})_{6}\right] / \mathrm{K}_{4}\left[\mathrm{Fe}(\mathrm{CN})_{6}\right]$ solution, which is a medium commonly used for Cyclic Voltammetry studies, electrochemical technique that is largely employed in biosensors researches [19,21,22] or even in Faradaic Electrochemical Impedance Spectroscopy (EIS) [24].

\section{Materials and Methods}

\section{Preparation of the Transducer Substrate}

A copper wire was welded on the backside of the 304 SS (geometrical area of $1 \mathrm{~cm}^{2}$ ), which has chemical composition of $\mathrm{Cr}$ (18\%-20\%), Ni (8.0\%-10.5\%), Mn (2.0\%), Si (1.0\%), N (0.1\%), C (0.08\%), P (0.05\%), S (0.03\%) and Fe (balance) [25]. The whole system was cold embedded in an insulating epoxy resin (Aka-Resin, Akasel). The surface of this electrode was then polished with silicon carbide emery papers of 400, 600, 800 and 1200 mesh respectively. After polishing, the steel was sonicated for $5 \mathrm{~min}$ in ethanol and deionized water in an ultrasonic bath.

Potentiodynamic anodic polarization: All the electrochemical measurements were performed in a potentiostat Princeton Applied Research Versa STAT 3 (AMETEK) using an electrochemical three-electrode cell consisting of the substrate as a working electrode, a platinum sheet counter-electrode and $\mathrm{Ag} / \mathrm{AgCl}(3 \mathrm{M} \mathrm{KCl})$ as a reference electrode. Potentiodynamic anodic polarization was performed to evaluate the corrosion resistance of the 304 SS. In this study, we evaluated four different electrolytes where the biosensors are commonly applied at their working condition, named:

a) Tris: $0.01 \mathrm{M}$ aqueous solution of Tris(hydroxymethyl)aminomethane, whose $\mathrm{pH}$ was adjusted to 7.4 with hydrochloric acid;

b) Electrolyte: Tris buffer containing $0.1 \mathrm{M} \mathrm{KCl}$ as supporting electrolyte;

c) Hanks' solution: electrolyte that simulates blood fluids. It is composed by $\mathrm{NaCl}\left(8 \mathrm{~g} . \mathrm{L}^{-1}\right), \mathrm{KCl}\left(0.4 \mathrm{~g} . \mathrm{L}^{-1}\right), \mathrm{MgSO}_{4} .7 \mathrm{H}_{2} \mathrm{O}(0.06$ g. $\left.\mathrm{L}^{-1}\right), \mathrm{MgCl}_{2} \cdot 6 \mathrm{H}_{2} \mathrm{O}\left(0.1\right.$ g.L $\left.\mathrm{L}^{-1}\right), \mathrm{CaCl}_{2}\left(0.14\right.$ g. $\left.\mathrm{L}^{-1}\right), \mathrm{Na}_{2} \mathrm{HPO}_{4} \cdot 2 \mathrm{H}_{2} \mathrm{O}$ (0.06 g. $\left.\mathrm{L}^{-1}\right), \mathrm{KH}_{2} \mathrm{PO}_{4}\left(0.06\right.$ g. $\left.\mathrm{L}^{-1}\right)$, glucose $\left(0.1\right.$ g. $\left.\mathrm{L}^{-1}\right)$ and $\mathrm{NaHCO}_{3}$ $\left(0.35\right.$ g. $\left.\mathrm{L}^{-1}\right)[26]$;

d) CV: solution employed in Cyclic Voltammetry tests (and in Faradaic EIS), it was prepared by adding $5 \mathrm{mM}$ of both $\mathrm{K}_{3}\left[\mathrm{Fe}(\mathrm{CN})_{6}\right] / \mathrm{K}_{4}\left[\mathrm{Fe}(\mathrm{CN})_{6}\right]$ in the electrolyte.
The $\mathrm{pH}$ and conductivity of these solutions were measured at $25^{\circ} \mathrm{C}$ by using a digital pHmeter pHtek model Phs $3 \mathrm{~b}$ and a conductivity meter mCA 150 (MS TECNOPON). Open Circuit Potential (OCP) was monitored for 1 hour before each anodic polarization measurement. The polarization tests were carried out at a scanning rate of $1 \mathrm{mV}^{-1} \mathrm{until}^{-1}$ the current density reached the value of $10^{-3}$ A. $\mathrm{cm}^{-2}$ after the breakdown potential.

Chronoamperometry Test: Chronoamperometry was performed to analyze the stability of the passive layer of the 304 SS in each solution. For this purpose, the constant potentials indicated in Table 1 were previously defined by the anodic polarization test (as the intermediary potential in the passive region) and applied to the working electrode during $16 \mathrm{~h}$ in the different media.

Table 1: Potentials applied to the 304 SS during 16h of Chronoamperometry in Tris, electrolyte, Hanks' solution and CV.

\begin{tabular}{|c|c|}
\hline Solution & E (V) vs Ag/AgCl \\
\hline Tris & 0.40 \\
\hline Electrolyte & 0.30 \\
\hline Hanks & 0.36 \\
\hline CV & 0.30 \\
\hline
\end{tabular}

Optical Microscopy Characterization: Images of Optical Microscopy of the substrates were registered before and after the chronoamperometric tests in each medium in order to analyze the surface morphology and the corrosion effect of the solutions in the SS. Thereunto, an optical microscope Bel Photonics model MTM17T was used with a magnification of 100 times.

\section{Preparation of the Biosensor and Analyte Recognition}

The substrate was functionalized by its immersion in an aqueous solution of (3-aminopropyl)triethoxysilane $1 \% \mathrm{v} / \mathrm{v}$, next in an aqueous solution of glutaraldehyde $(1 \% \mathrm{v} / \mathrm{v})$ and, then, in a 10 $\mu \mathrm{g} . \mathrm{mL}^{-1}$ solution of antibodies raised in hyperimmunized horses against the venom of Crotalus durissus terrificus snake (diluted in $0.01 \mathrm{M}$ Tris buffer, $\mathrm{pH}$ 7.4). Finally, the substrate was immersed in a Bovine Serum Albumin (BSA) solution at $1 \% \mathrm{w} / \mathrm{v}$ in Tris buffer to block nonspecific binding sites. All the functionalizing steps were carried out for $1 \mathrm{~h}$ and after each of them, the device was washed with Tris buffer to remove the excess of reagents.

To evaluate the capability of the biosensor to recognize its analyte of interest, EIS was performed before and after the incubation of the devices in a $10 \mu \mathrm{g}$. $\mathrm{mL}^{-1}$ crotalic venom solution, which was prepared using Hanks' solution in order to simulate the real condition of an envenomed patient. EIS was performed ranging the frequency from $10^{4}$ to $10^{-2} \mathrm{~Hz}$ at a $10 \mathrm{mV}$ amplitude potential after an OCP stabilization time of $1 \mathrm{~h}$. The impedance data was fitted using the Zview software version 2.9b (Scribner and Associates) by simulating the results in comparison to an equivalent electrical circuit.

\section{Capacitance Analysis of the SS}

To assess the semiconducting properties of the SS in the various media under investigation, a Mott-Schottky test was performed in 
a potential range from -0.2 to $+1.1 \mathrm{~V} \mathrm{vs} \mathrm{Ag} / \mathrm{AgCl}$ with a $66 \mathrm{mV}$ step height at $1000 \mathrm{~Hz}$ according to the methodology described by other authors who studied the electrochemical properties of SSs [27-29]. By means of this technique, it was possible to estimate the concentration of charge donors and acceptors in the SS.

\section{Results and Discussion}

\section{Potentiodynamic Anodic Polarization Study}

The $\mathrm{pH}$ and conductivity of the four media were measured and the results are shown in Table 2. All the solutions were neutral, and the conductivity values presented the more significant differences. Because of the ions concentration in each solution, the Tris buffer was the less conductive medium and the CV solution was the one with the higher conductivity.

Table 2: Values of $\mathrm{pH}$ and conductivity for Tris, electrolyte, Hanks' solution and CV solution.

\begin{tabular}{|c|c|c|c|c|}
\hline & Tris HCl & Electrolyte & Hanks' Solution & CV solution \\
\hline $\mathrm{pH}$ & 7.4 & 7.4 & 7.2 & 7.4 \\
\hline $\begin{array}{c}\text { Conductivity } \\
\text { (mS.cm }^{-1)}\end{array}$ & 0.9085 & 13.04 & 14.94 & 15.96 \\
\hline
\end{tabular}

Figure 1 displays the polarization plots referring to the 304 SS exposed to Tris, electrolyte, Hanks' solution and CV solution at $25^{\circ} \mathrm{C}$. The different shapes of the plots indicate that the $304 \mathrm{SS}$ showed different corrosion mechanisms in the different media. In Tris and Hanks' solution, the polarization current densities started from a relatively small value before the pitting development and, after increasing the potential at an almost constant current density value, a significant increasing of the current took place again due to the breakdown of the previously formed passive layer on the steel surface by the presence of aggressive ions from the bulk solution [30]. Despite cyclic potentiodynamic polarizations was not carried out in this study, it is possible to observe that in a density current of $10^{-3} \mathrm{~A}$, the $304 \mathrm{SS}$ presented a trend of positive hysteresis, indicating the possibility of pitting repassivation in an eventual reverse scan potential.

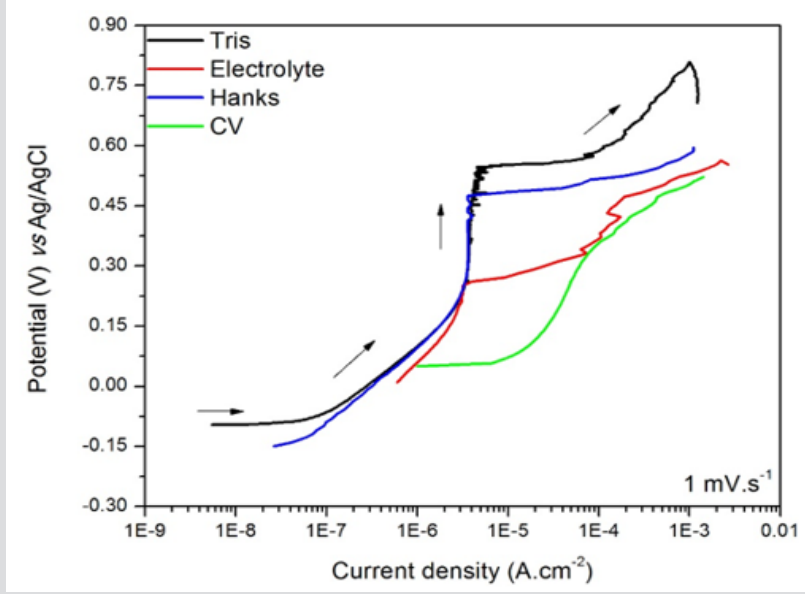

Figure 1: Polarization plots of the 304 SS in Tris (A), electrolyte (B), Hanks' solution (C) and CV solution (D).
In a neutral aerated medium, such as employed in this work, the cathodic reaction that occur in the SS is the oxygen reduction as follows [30]:

$$
2 \mathrm{H}_{2} \mathrm{O}_{(I)}+\mathrm{O}_{2(g)}+4 e^{-} \rightarrow 4 \mathrm{OH}_{(a q .)}^{-}
$$

The correspondent anodic reaction in a SS is the dissolution of the iron, in which the liberated electrons are consumed in the cathode according to the reaction:

$$
F e_{(s)} \rightarrow \mathrm{Fe}_{(a q .)}^{2+}+2 e^{-}
$$

Concerning the electrolyte, two passivation potentials $\left(\mathrm{E}_{\text {pass }}\right)$ may be assumed: one at $0.25 \mathrm{~V}$ vs $\mathrm{Ag} / \mathrm{AgCl}$ and other at $0.48 \mathrm{~V}$ vs $\mathrm{Ag} / \mathrm{AgCl}$. It indicates a possible presence of secondary passivation or pseudo passivation in which the first $\mathrm{E}_{\text {pass }}$ value is lower than that one observed in Tris, while the second $\mathrm{E}_{\text {pass }}$ value is similar to the one seen in Tris. During the second passivation stage, there was an instable region where the current did not assume a progressive increasing, but it was affected probably by a sequence of formation and dissolution of the passive film. As expected, the electrolyte was more aggressive than the Tris because it contains $\mathrm{KCl}$ as supporting electrolyte (presenting higher conductivity), which solubilizes in the water forming $\mathrm{Cl}^{-}$ions, anions that are responsible for the pitting corrosion in SSs [31].

In $\mathrm{CV}$ solution, the steel did not present a well-defined $\mathrm{E}_{\text {pass }}$ although a potential increasing occurred in density currents between $10^{-5}$ and $10^{-4} \mathrm{~A} \cdot \mathrm{cm}^{-2}$, characteristic range of passivation in corrosion processes. Wolynec [32] suggests that in low current density values, around $10^{-6}{\mathrm{~A} . \mathrm{cm}^{-2}}$ for instance, the material does not suffer corrosion because it is protected by the passive film. The combination of the higher corrosion potential $\left(\mathrm{E}_{\text {corr }}=-0.099 \pm 0.002 \mathrm{~V}\right.$ vs Ag/ $\mathrm{AgCl})$ and pitting potential $\left(\mathrm{E}_{\text {pit }}=0.500 \pm 0.061 \mathrm{~V} \mathrm{vs} \mathrm{Ag} / \mathrm{AgCl}\right)$ of the steel polarized in Tris indicates that this solution was the less aggressive in comparison to the others. The CV solution was the most aggressive medium due to its higher concentration of ions (higher conductivity) that hinders the development of the passive film to protect the steel surface.

\section{Chronoamperometric Behavior of the SS}

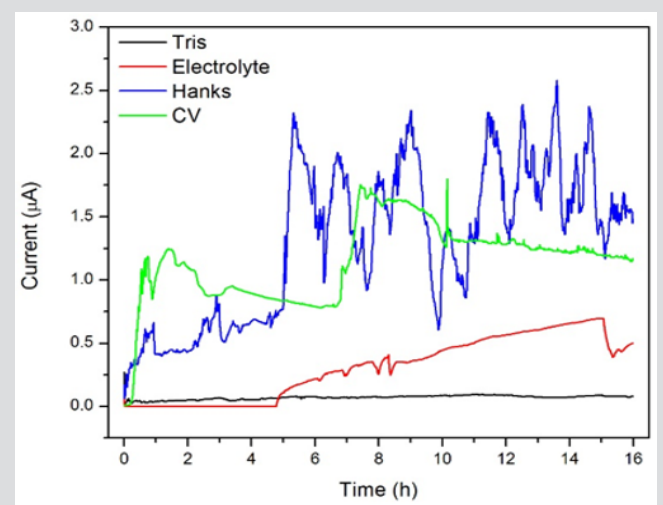

Figure 2: Chronoamperometry plots of the $304 \mathrm{SS}$ exposed to: (A) Tris, (B) electrolyte (C) Hanks' solution and (D) CV solution. 
Regarding the biosensing applications, the chemical stability of a material is an important parameter to be taken in account because the occurrence of oxidative/reductive reactions at the sensor's surface can compromise characteristics such as its sensitivity and reproducibility. Accordingly, the chemical stability of a material is related to its lifetime and may limit its technological application. In order to evaluate the stability of the $304 \mathrm{SS}$ in the different media, chronoamperometry was performed in Tris, electrolyte, Hanks' solution and CV solution. The results are shown in Figure 2.

Some current fluctuations occurred in function of the time due to the exposition of the steel to the electrolyte, the Hanks' solution and the CV solution. González and Saidman [33] affirmed that this kind of behavior is characteristic of localized (pitting) corrosion. In Hanks' solution, it is possible to observe that the steel did not achieve the stationary condition under the influence of the fixed 0.3 $\mathrm{V}$ potential since there was a continuous current increasing along the time. Alentejano and Aoki [34] observed the same chronoamperometric behavior of the 304 SS in a medium rich in chloride ions, attributing the instability to the formation of stable pits after the rupture of the passive film.

In consonance to the results discussed in the previous sections, the chronoamperometry results demonstrated that the Hanks' and CV solutions were the most aggressive media to the SS due to the high current values achieved during the test (around $10^{-3} \mathrm{~A}$ ). The images of Optical Microscopy in Figure 3, in which it is possible to note the more significant presence of corrosion products in the SS when it was exposed to Hanks' and CV solutions, corroborate the higher aggressiveness of these media. However, the SS presented good stability in Tris along the whole experiment and in electrolyte in the first five hours. Considering that the chronoamperometry was performed under the influence of a critical potential in each solution, one can infer about the stability of the SS in applications in which it is required the application of potential to the sensor (in amperometric transduction for example). In this sense, techniques performed at the equilibrium (i.g. non-faradaic EIS) are more appropriated to fit the SS application.

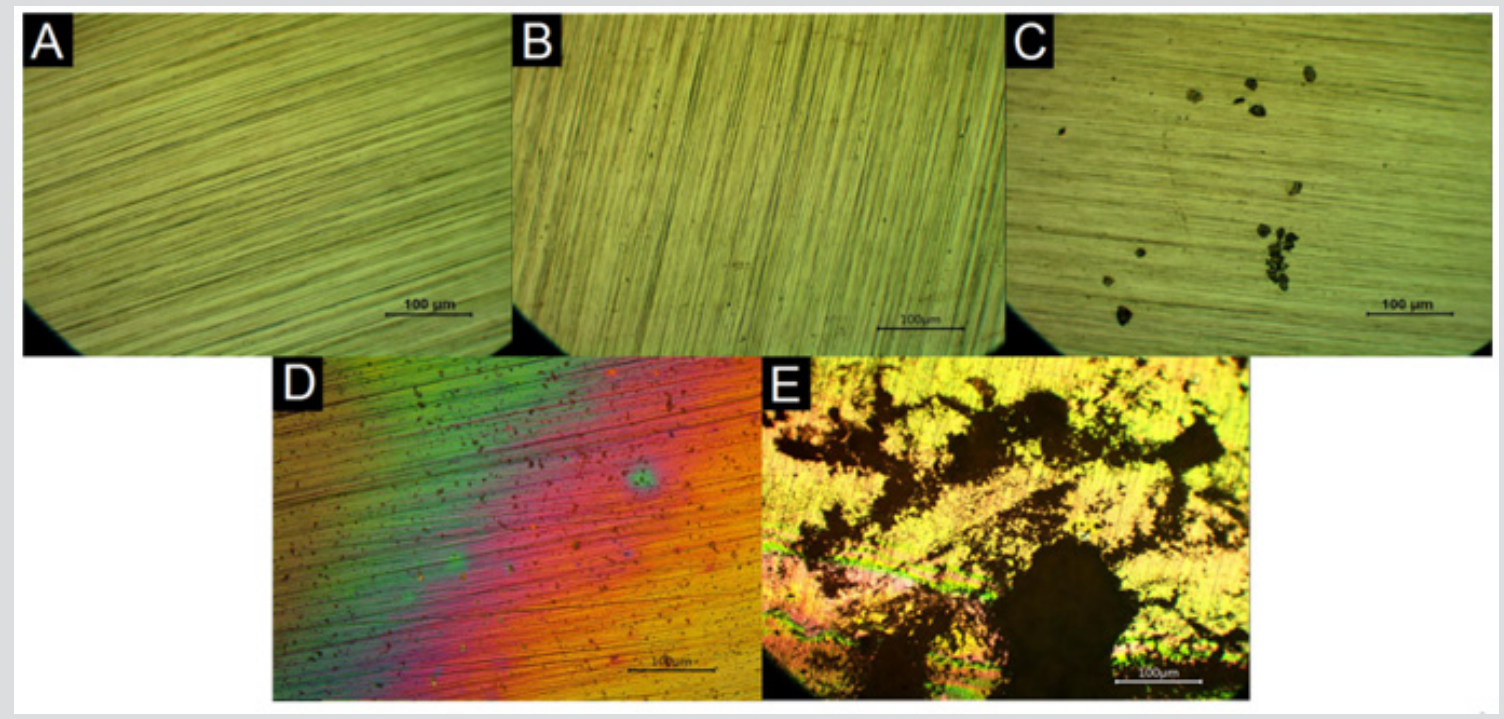

Figure 3: Images of Optical Microscopy of the 304 SS before (A) and after chronoamperometry tests in Tris (B), electrolyte (C), Hanks' solution (D) and CV solution (E) (magnification of 100x).

\section{Analysis of the Semiconducting Properties of the SS}

Since the Mott-Schottky relation is a function of the applied potential (E), it was possible to inspect the semiconducting features of the SS in the various media. In Eq.1 and Eq. 2, "C" refers to the space charge layer capacitance, "e" is the charge of the electron (equal to $\left.1.6 \times 10^{-19} \mathrm{C}\right)$, " $\varepsilon$ " is the dielectric constant of the SS $(\varepsilon=12)$, " $\varepsilon_{0}$ " is the vaccum permittivity $\left(8.854 \times 10^{-12} \mathrm{~F}^{-1} \mathrm{~m}^{-1}\right)$, "A" is the surface area of the SS electrode, " $\mathrm{E}_{\mathrm{fb}}$ " is the flat band potential, " $\mathrm{k}$ " is the Boltzmann constant $\left(1.38 \times 10^{-23} \mathrm{~J} . \mathrm{K}^{-1}\right)$, "T" is the temperature in Kelvin and " $\mathrm{N}_{\mathrm{D}}$ " and " $\mathrm{N}_{\mathrm{A}}$ " are, respectively, the donors and acceptors concentrations of the material under investigation $[35,36]$.

$$
\frac{1}{C^{2}}=\left(\frac{2}{e \varepsilon \varepsilon_{0} N_{D}}\right) \cdot\left(-E+E_{f b}-\frac{\kappa T}{e}\right)
$$

$$
\frac{1}{C^{2}}=-\left(\frac{2}{e \varepsilon \varepsilon_{0} N_{A}}\right) \cdot\left(-E+E_{f b}-\frac{\kappa T}{e}\right)(\text { Eq.6) }
$$

In case of negative slope, it is assumed that the material is a p-type semiconductor, and in case of positive slope, the material is an n-type semiconductor. Linear relations were found between the $\mathrm{C}^{-2}$ and the applied potential in Figure 4a, which indicates that the SS possess semiconducting properties in the studied media [37]. The SSs assumed both behaviors. In potentials up to $+0.3 \mathrm{~V}$ vs Ag/ $\mathrm{AgCl}$, the negative slope of the $\mathrm{C}^{-2} \mathrm{vs}$ E curve associated to the p-type semiconductor arises from the inner oxides film formed on the SS surface, which are rich in chromium. On the other hand, the n-type behavior (positive slope from +0.3 to $+1.1 \mathrm{~V}$ vs $\mathrm{Ag} / \mathrm{AgCl}$ ) is related to the more external layer containing iron oxides and hydroxides [38]. 
In SSs, the semiconducting behavior arises from the formation of the passive layer. Oxide films formed during the passivation consist of organized crystallographic structure that presents an insulating character due to its stoichiometry. However, the presence of localized defects in the film, such as the cationic vacancies $\left(V_{M} \chi^{\prime}\right)$, oxygen vacancies $\left(v_{0}\right)$ and interstitial vacancies can lead the material to behave as an extrinsic semiconductor in aqueous medium. The Kroger-Vink notations ( $\bullet$ and $\chi^{\prime}$ ) correspond to, respectively, the negative/positive charges and the cationic vacancies [39-41] The cationic vacancies are electron acceptors and lead to a p-type doping, while the oxygen vacancies and interstitial cations are electron donors, which are responsible for the n-type doping [42].

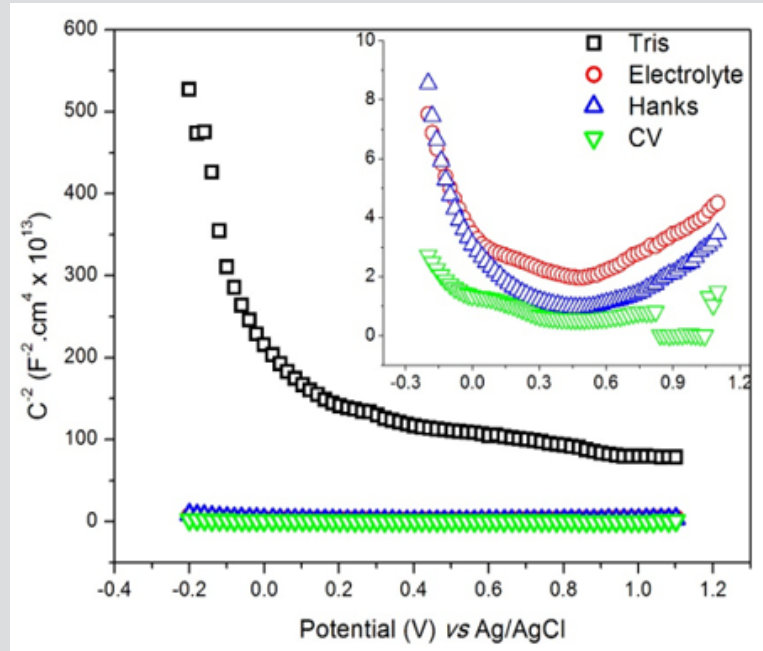

Figure 4: Mott-Schottky plots of the 304 SS exposed to Tris, electrolyte, Hanks' and CV solutions from -0.2 to $+1.1 \mathrm{~V}$ vs $\mathrm{Ag} / \mathrm{AgCl}$ at $1000 \mathrm{~Hz}$.

\section{Performance of the SS-Based Biosensor towards a Target Analyte}

Aiming to study the recognition capability of the SS-based biosensor, EIS data was modelled to a suitable electrical equivalent circuit. A Randles model consisting of an Electrolyte Resistance (Re), a Constant Phase Element (CPE), which is used instead of a pure capacitor due to the irregularities of the substrate's surface, such as its heterogeneity and roughness [43], and leakage resistance (Rleak) was used to simulate the impedance data. The fitting quality was ensured by the low values of the statistic parameter chisquared $\left(\chi^{2}\right)$ for all the EIS measurements, presenting an average value of $3.15 \times 10^{-3} \pm 4.53 \times 10^{-4}$

Figure 5 shows the Nyquist Diagram for the biosensor containing the SS as a substrate before and after the exposure to the analyte. The results revealed an increasing of the capacitive arc diameter after the incubation in the analyte solution, which is related to the difficult of charge transferring on the interface electrode-electrolyte due to the presence of pair antigen-antibody, forming a more insulating layer. Elshafey et al. [44] confirmed that the formation of the immune complex antigen-antibody hinders the capability of ions from electrolyte to penetrate its interface with the electrode, enhancing the charge transfer Resistance (Rct) in case of a faradaic sensors. In case of non-Faradaic sensors, in which there is no redox species in the electrolyte, when the antibodies present on the SS surface binds the target antigen (crotalic venom in this work), this captured analyte acts diminishing the conductivity of the transducer substrate [24]. In this sense, an expected increasing of Rleak $(95.00 \pm 8.71 \%)$ was observed from the biosensor before and after its incubation in the analyte solution, confirming that the SS is an adequate electrochemical transducer to be used in biosensors. In our previous publication [45], we have exploited further characteristics (limit of detection, sensitivity and selectivity) of a sensor developed by means of a SS (Crofer $22 \mathrm{APU}$ ) towards the detection of venom from Bothrops snakes, corroborating the usability of these material for biosensing applications.

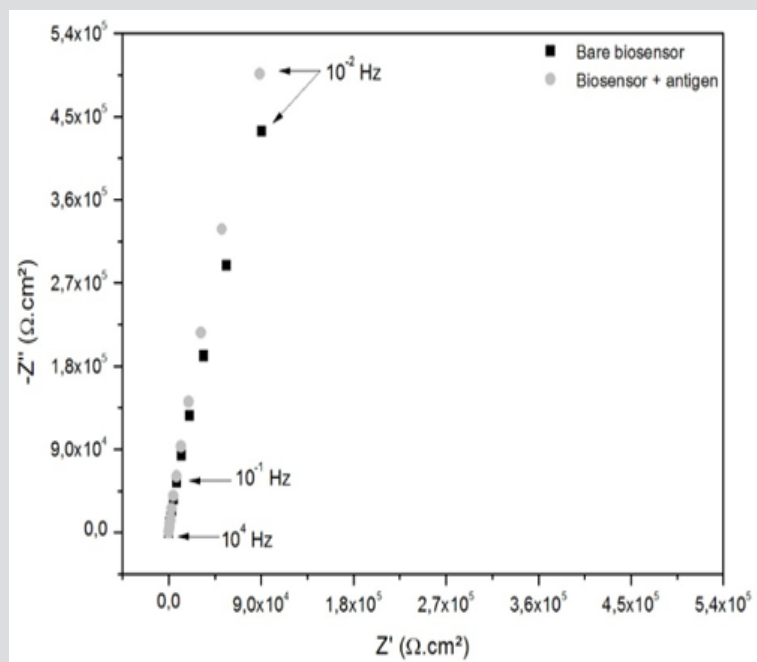

Figure 5: Nyquist Diagram of the SS-based biosensor before and after exposure to a target analyte (crotalic venom at $10 \mu \mathrm{g}$. $\mathrm{mL}^{-1}$ diluted in Hanks' solution).

\section{Conclusion}

The electrochemical characteristics of a 304 SS were investigated in order to evaluate it as an electrochemical matrix for biosensing applications. Tris buffer, electrolyte, Hanks' solution and CV solution simulated the conditions in which electrochemical biosensors are commonly employed in the literature. The corrosion tests indicated that the Hanks' and CV solutions represented the most aggressive media to the SS electrode. The presence of corrosion products on the surface of the electrode especially after polarization in these both solutions could limit the application of SSs in biosensors whose transducer mechanism depends on the application of critical potentials. Mott-Schottky analysis demonstrated that the corrosion products on the surface of the SS presents semiconducting features due to the presence of donors and acceptors carriers that provide both n- and p-type behaviors. Finally, after functionalizing the SS to recognize the presence of a target analyte in Hanks' solution, the developed sensor suffered an increase of $95.00 \pm 8.71 \%$ in the leakage resistance due to the formation of an insulating layer consisting of the immune complex crotalic venom/ anticrotalic antibodies. Thus, the chemical stability of the SS in all the solutions at 
the electrochemical equilibrium and under the application of critical potentials mainly in Tris and electrolyte as well as its capability to recognize a biomolecule of interest after functionalization allow to affirm that the SS is a promising transducer substrate for application in electrochemical biosensors.

\section{Acknowledgement}

The authors thank the Coordenação de Aperfeiçoamento de Pessoal de Nível Superior (CAPES) for the financial support.

\section{References}

1. Compagnone D, Di Francia G, Di Natale C, Neri G, Seeber R, et al. (2017) Chemical Sensors and Biosensors in Italy: A Review of the 2015 Literature. Sensors 17(4): 868.

2. Daniel R Thévenot, Klara Toth, Richard A. Durst, George S Wilson (1999) Electrochemical biosensors: Recommended definitions and classification. Biosensors and Bioelectronics 71(12): 2333-2348.

3. Perumal V, Hashim U (2014) Advances in biosensors: principle, architecture and applications. J Appl Biomed 12: 1-15.

4. Turner AP (2013) Biosensors: Sense and sensibility. Chem Soc Rev 42(8): 3184-3196.

5. Ahmed MU, Saaem I, Wu PC, Brown AS (2013) Personalized diagnostics and biosensors: A review of the biology and technology needed for personalized medicine. Crit Rev Biotech 34(2):180-196.

6. Lopez GA, Estevez MC, Soler M, Lechuga LM (2017) Recent advances in nanoplasmonic biosensors: applications and lab-on-a-chip integration. Nanophot 6(1): 123-126.

7. Manera MG, Pellegrini G, Lupo P, Bello V, Fernández CJ, et al. (2017) Functional magneto-plasmonic biosensors transducers: Modelling and nanoscale analysis. Sens Act B Chem 239: 100-112.

8. Rezaei B, Shams-Ghahfarokhi L, Havakeshian E, Ensafi AA (2016) An electrochemical biosensor based on nanoporous stainless steel modified by gold and palladium nanoparticles for simultaneous determination of levodopa and uric acid. Talanta 158: 42-50.

9. Mariotto SF F, Guido V, Cho LY, Soares CP, Cardoso KR (2011) Porous stainless steel for biomedical applications. Mat Res 14(2): 146-154.

10. Kitte SA, Gao W, Zholudov YT, Qi L, Nsabimana A, et al. (2017) Stainless steel electrode for sensitive luminol electrochemiluminescence detection of $\mathrm{H}_{2} \mathrm{O}_{2}$, glucose, and glucose oxidase activity. Anal Chem 89(18): 9864-9869.

11. Li H, Wang C, Wang X, Hou P, Luo B, et al. (2019) Disposable stainless steel-based electrochemical microsensor for in vivo determination of indole-3-acetic acid in soybean seedlings. Bios Bioelectron 126: 193199.

12. Vanlinden MR, Niere M, Nikiforov AA, Ziegler M, Dölle C (2017) Compartment-Specific Poly-ADP-ribose formation as a biosensor for subcellular NAD pools. Methods Mol Biol 16(8): 45-56.

13. Ding L, Qin Z, Xiang C, Zhou G (2017) Novel fluorescent organic nanoparticles as a label-free biosensor for dopamine in serum. J Mat Chem B 5: 2750-2756.

14. Idil N, Hedström M, Denizli A, Mattiasson B (2017) Whole cell based microcontact imprinted capacitive biosensor for the detection of Escherichia coli. Bios Bioelectron 87: 807-815.

15. Wilson TA, Musameh M, Kyratzis IL, Zhang J, Bond AM, et al. (2017) Enhanced NADH oxidation using polytyramine/carbon nanotube modified electrodes for ethanol biosensing. Electroanal 29(8): 19851993.

16. Zlámalová M, Janda P, Nesměrák K (2017) Hydrogen sulfide detection by poly(methylene blue) modified highly oriented pyrolytic graphite electrode. Monatshefte für Chemie - Chem Month 148(9): 1595-1597.
17. Tkacz J, Slouková K, Minda J, Drábiková J, Fintová S, et al. (2017) Influence of the composition of the hank's balanced salt solution on the corrosion behavior of AZ31 and AZ61 magnesium alloys. Metals 7: 465.

18. Siu HT, Man HC (2013) Fabrication of bioactive titania coating on nitinol by plasma electrolytic oxidation. Appl Surf Sci 274: 181-187.

19. Mir RA, Shinohara H (2017) Two-dimensional surface plasmon resonance imaging system for cellular analysis. Methods Mol Biol 1571: $31-46$

20. Palygin O, Levchenko V, Evans LC, Blass G, Cowley AW, et al. (2015) Use of enzymatic biosensors to quantify endogenous ATP or $\mathrm{H}_{2} \mathrm{O}_{2}$ in the kidney. J Vis Exp 12: 104.

21. Wei Y, Liu XP, Mao C, Niu HL, Song JM, et al. (2018) Highly sensitive electrochemical biosensor for streptavidin detection based on $\mathrm{CdSe}$ quantum dots. Bios Bioelectron 103: 99-103.

22. Toh RJ, Mayorga-Martinez CC, Sofer Z, Pumera M (2017) 1T-Phase WS protein-based biosensor. Adv Func Mat 27(5).

23. Liu Q Ma C, Liu XP, Wei YP, Mao CJ, et al. (2017) A novel electrochemiluminescence biosensor for the detection of microRNAs based on a DNA functionalized nitrogen doped carbon quantum dots as signal enhancers. Bios Bioelectron 92: 273-279.

24. Faria RAD, Heneine LGD, Matencio T, Messaddeq Y (2019) Faradaic and non-faradaic electrochemical impedance spectroscopy as transduction techniques for sensing applications. Int J Bios Bioelectron 5(1): 29-31.

25. Alves JO, Tenório JAS, Zhuo C, Levendis YA (2012) Use of stainless steel AISI 304 for catalytic synthesis of carbono nanomaterials from solid wastes. J Mat Res Tech 1(3): 128-133.

26. Feng X, Lu X, Guo L, Chen D (2015) The effects of deformation on corrosion behavior of stainless steel in chlorides contaminated concrete pore solution. Int J Electrochem Sci 10: 10677-10688.

27. Feng X, Lu X, Zuo Y, Zhuang N, Chen D (2016) The effect of deformation on metastable pitting of 304 stainless steel in chloride contaminated concrete pore solution. Corr Sci 103: 223-229.

28. Zou G, Shi W, Xiang S, Ju X, Ma G, et al. (2018) Corrosion behavior of 904L austenitic stainless steel in hydrofluoric acid. Royal Soc Chem 8: 2811-2817.

29. Tian W, Du N, Li S, Chen S, Wu Q (2014) Metastable pitting corrosion of 304 stainless steel in 3.5\% NaCl solution. Corr Sci 85: 372-379.

30. Sherif ESM, Potgieter J, Comins JD, Cornish L, Olubambi PA, et al. (2009) The beneficial effect of ruthenium additions on the passivation of duplex stainless-steel corrosion in sodium chloride solutions. Corr Sci 51: 1364-1371.

31. Cheng CQ Klinkenberg LI, Ise Y, Zhao J, Tada E, et al. (2017) Pitting corrosion of sensitised type 304 stainless steel under wet-dry cycling condition. Corr Sci 118: 217-226.

32. Wolynec S (2003) Electrochemical Techniques in Corrosion. Edusp, Brasil pp. 166.

33. González MB, Saidman SB (2011) Electrodeposition of polypyrrole on 316L stainless steel for corrosion prevention. Corr Sci 53: 276-282.

34. Alentejano CR, Aoki IV (2004) Localized corrosion inhibition of 304 stainless steel in pure water by oxyanions tungstate and molybdate. Electrochim Acta 49: 2779-2785.

35. Bianchi S, Trueba M, Trasatti SP, Madaschi E, Sala MC (2014) An in-depth comprehension of the protection mechanism of Al alloys by anilinebased silane. Prog Org Coat 77 (12-A): 2054-2065.

36. Hamadou L, Kadri A, Benbrahim N (2010) Impedance investigation of thermally formed oxide films on AISI 304L stainless steel. Corr Sci 52(3): 829-864.

37. Metikoš-Huković M, Katić J, Grubač Z, Rončević Š (2017) Electrochemistry of CoCrMo implant in hanks' solution and mott-schottky probe of alloy's passive films. Corr 73(12): 1401-1412. 
38. Pieretti EF, Neves MDM (2017) Laser marked and textured biomaterial evaluated by Mott-Schottky technique. Int J Electrochem Sci 12: 9204 9211.

39. Mîndroiu M, Ungureanu C, Ion R, Pîrvu C (2013) The effect of deposition electrolyte on polypyrrole surface interaction with biological environment. Appl Surf Sci 276: 401-410.

40. Férnandez-Domene RM, Blasco-Tamarit E, García-García DM, GarcíaAntón J (2014) Effect of alloying elements on the electronic properties of thin passive films formed on carbon steel, ferritic and austenitic stainless steels in a highly concentrated LiBr solution. Thin Sol Films 558: 252-258.

41. Yang S, Macdonald DD (2007) Theoretical and experimental studies of the pitting of type 316L stainless steel in borate buffer solution containing nitrate ion. Electrochim Acta 52: 1871-1879.

\section{ISSN: 2574-1241}

DOI: 10.26717/BJSTR.2019.18.003117

Ricardo Adriano Dorledo de F. Biomed J Sci \& Tech Res

(c) (P) This work is licensed under Creative

Submission Link: https://biomedres.us/submit-manuscript.php
42. Fattah-Alhosseini A, Vafaeian S (2015) Comparison of electrochemical behavior between coarse-grained and fine-grained AISI 430 ferritic stainless steel by Mott-Schottky analysis and EIS measurements. J Alloys Comp 639: 301-307.

43. Rezaei B, Havakeshian E, Ensafi AA (2013) Stainless steel modified with an aminosilane layer and gold nanoparticles as a novel disposable substrate for impedimetric immunosensors. Bios Bioelectron 48: 61-66.

44. Elshafey R, Tlili C, Abulrob A, Tavares AC, Zourob M (2013) Label-free impedimetric immunosensor for ultrasensitive detection of cancer marker Murine double minute 2 in brain tissue. Bios Bioelectron 39: 220-225.

45. Faria RA D, Lins VF C, Nappi GU, Matencio T, Heneine LG D (2018) Development of an impedimetric immunosensor for specific detection of snake venom. Bio Nano Sci 8(4): 988-996.

$\begin{array}{ll}\text { BIOMEDICAL } & \text { Assets of Publishing with us } \\ \text { RESEARCHES } & \text { - Global archiving of articles } \\ & \text { - Immediate, unrestricted online access } \\ \end{array}$

